\title{
AZD8055 Exerts Antitumor Effects on Colon Cancer Cells by Inhibiting mTOR and Cell-cycle Progression
}

\author{
YUN CHEN $^{1,2^{*}}$, CHENG-HUNG LEE $^{3,4^{*}}$, BOR-YUAN TSENG $^{1}$, YA-HUI TSAI ${ }^{1,2,5}$, \\ HUANG-WEN TSAI ${ }^{1}$, CHAO-LING YAO ${ }^{2,3}$ and SHENG-HONG TSENG ${ }^{6}$ \\ ${ }^{1}$ Department of Surgery, Far Eastern Memorial Hospital, New Taipei, Taiwan, R.O.C.; \\ ${ }^{2}$ Department of Chemical Engineering and Materials Science, and ${ }^{3}$ Graduate School of \\ Biotechnology and Bioengineering, Yuan Ze University, Taoyuan, Taiwan, R.O.C.; \\ ${ }^{4}$ Department of General Surgery, Buddhist Dalin Tzu Chi Hospital, Chia-Yi \\ and School of Medicine, Tzu Chi University, Hualien, Taiwan, R.O.C.; \\ ${ }^{5}$ Department of Materials and Textiles, Oriental Institute of Technology, New Taipei, Taiwan, R.O.C.; \\ ${ }^{6}$ Department of Surgery, National Taiwan University Hospital, and National \\ Taiwan University College of Medicine, Taipei, Taiwan, R.O.C.
}

\begin{abstract}
Background/Aim: AZD8055 is an inhibitor of mammalian target of rapamycin (mTOR) that can suppress both mTOR complex 1 (mTORC1) and mTORC2. This study investigated the antitumor effects of AZD8055 on colon cancer. Materials and Methods: The effects of AZD8055 on proliferation, apoptosis, and cell cycle of colon cancer cells, and tumor growth in a mouse colon cancer model were studied. Results: AZD8055 significantly inhibited proliferation and induced apoptosis of colon cancer cells $(p<0.05)$. The phosphorylation of both AKT and S6 kinase 1 (S6K1) was suppressed by AZD8055. AZD8055 also induced $G_{0} / G_{1}$ cell-cycle arrest, reduced cyclin D1 and increased p27 expression, and suppressed the levels of phospho-cyclindependent kinase 2 and phospho-retinoblastoma. Compared to the control, oral administration of AZD8055 significantly suppressed tumor growth in mice $(p<0.05)$. Conclusion: AZD8055 induces cytotoxicity, apoptosis, and cell-cycle arrest of colon cancer cells, and exerts an antitumor effect
\end{abstract}

*These Authors contributed equally to this study.

Correspondence to: Dr. Chao-Ling Yao, Department of Chemical Engineering and Materials Science, Yuan Ze University, No. 135, Yuan-Tung road, Chung-Li District, Taoyuan City 32003, Taiwan. Tel: $\quad+886$ 34638800, Fax: +886 34559373, e-mail: d897601@alumni.nthu.edu.tw, yao@saturn.yzu.edu.tw; or Dr. ShengHong Tseng, Department of Surgery, National Taiwan University Hospital and National Taiwan University College of Medicine, 7 Chung-Shan S. Rd., Taipei 100, Taiwan. Tel: +886 223123456, ext. 65110, Fax: +886 289665567, e-mail: shenghongtseng@gmail.com

Key Words: AZD8055, colon cancer, mTOR, apoptosis, cell cycle. in mice. It also inhibits the mTOR signaling pathway and mTOR-dependent cell-cycle progression.

Colon cancer is one of the leading causes of cancer death in the world $(1,2)$. Many genetic alterations have been noted in colon cancer, including Ras activation, phosphatidylinositol 3-kinase (PI3K) pathway hyperactivation, p53 mutation, and dysregulation of the Wnt pathway (2, 3). Among these genetic changes, dysregulation of the PI3K/protein kinase B $(\mathrm{AKT}) /$ mammalian target of rapamycin (mTOR) signaling pathway occurs in about $60-70 \%$ of human colon cancer cases (4). Because mTOR activation is an early and common event in colon cancer, $\mathrm{mTOR}$ has become a therapeutic target for colon cancer therapy $(2,5-7)$. The mTOR kinase forms two complexes, known as mTOR complex 1 (mTORC1) and mTORC2, with the regulatory-associated protein of mTOR (RAPTOR) or rapamycin-insensitive companion of mTOR (RICTOR), respectively (8-10). mTORC1 functions through phosphorylation of eukaryotic initiation factor 4E-binding protein 1 (4E-BP1) and S6 kinase 1 (S6K1) (8-10). mTORC2 activation results in the phosphorylation of AKT, which in turn increases the activity of mTORC1 (8-10). Although mTOR inhibitors have undergone clinical trials for the treatment of various malignancies, rapamycin and its analogs (rapalogs) have been found to have only modest antitumor effects in single-agent therapy trials $(8,10)$. The limited clinical effect of rapalogs is considered to be related to the enhanced AKT activity that occurs due to a lack of mTORC2 inhibition, which may then cause drug resistance in tumor cells $(8,11)$.

AZD8055, an ATP-competitive mTOR kinase inhibitor, can suppress the phosphorylation of the mTORC1 substrates 
S6K and 4E-BP1, as well as phosphorylation of the mTORC2 substrate AKT and downstream proteins (8, 12, 13). AZD8055 shows excellent selectivity (approximately 1,000-fold) against all class I PI3K isoforms and other members of the PI3K-related kinase family, and had no significant activity against a panel of 260 kinases at concentrations up to $10 \mu \mathrm{M}(8)$. It is orally bioavailable and rapidly absorbed from the gastrointestinal tract $(14,15)$. The inhibition of both mTORC1 and mTORC 2 by AZD8055 may overcome the rapamycin-insensitivity of mTOR resulting from incomplete inhibition of mTOR activity [i.e. inhibition of mTORC1, but not mTORC2) by rapamycin $(10,16,17)]$. AZD8055 has been shown to have antiproliferative effects on different cancer types, including acute myeloid leukemia, neuroblastoma, pancreatic cancer, hepatocellular carcinoma, renal cell carcinoma, glioma, breast cancer, non-small cell lung cancer, prostate cancer, and uterine sarcoma $(8,11,12$, 14, 15, 18-24). Most studies have reported that AZD8055 achieved these antitumor effects at nanomolar drug levels (8, 11-13, 18, 25-27).

In this study, we investigated the effects of AZD8055 on AZD8055-resistant colon cancer cells in vitro. The effects of AZD8055 on cytotoxicity, apoptosis, and cell-cycle distribution, and the related mechanisms were explored. We also studied the in vivo effect of AZD8055 on tumor growth in a syngeneic mouse colon cancer model.

\section{Materials and Methods}

Cell lines. Human colon cancer cells HCT-15 and HCT-116 were gifts from Dr. J-H Chuang at Kaohsiung Chang Gung Memorial Hospital. Mouse CT-26, a syngeneic murine colon adenocarcinoma cell line induced in BALB/c mice by $N$-nitroso- $N$-methylurethane, was purchased from the American Tissue Culture Collection, (Rockville, MD, USA) (28).

AZD8055 preparation. AZD8055 was purchased from AstraZeneca (Wilmington, DE, USA). For in vitro experiments, AZD8055 powder was dissolved in dimethylsulfoxide (DMSO) at a concentration of $100 \mathrm{mM}$ as the stock solution. The stock solution aliquots were protected from light and stored at $-20^{\circ} \mathrm{C}$. For in vivo use, AZD8055 powder was mixed with $30 \%$ captisol solution (Captisol, San Diego, CA, USA) to reach a final concentration of $2 \mathrm{mg} / \mathrm{ml}$. The AZD8055captisol solution was stored at $4^{\circ} \mathrm{C}$ in small aliquots. For administration, the aliquots needed for daily dosing were pre-warmed in a $37^{\circ} \mathrm{C}$ water-bath for $10 \mathrm{~min}$ and gently vortexed immediately before use.

Cell viability. To elucidate the cytotoxic effects of AZD8055 on colon cancer cells, cells were seeded in a 24 -well plate, with $5 \times 10^{4}$ cells per well, and cultured for $24 \mathrm{~h}$. Cells were then separated into different treatment groups with six replicates in each group and incubated with different concentrations of AZD8055 for 24 or $48 \mathrm{~h}$. The media were then replaced with fresh media without drugs and cells were cultured for an additional $72 \mathrm{~h}$. Cell viability with different treatment regimens was analyzed using a 3-[4,5- dimethylthiazol-2-yl]-2,5-diphenyltetrazolium bromide (MTT)based colorimetric assay. The drug concentration at which $50 \%$ of cells were killed was designated as the $\mathrm{LC}_{50}$ value. Differences in the levels of cytotoxicity induced by various regimens were then compared.

Apoptosis analysis. The fraction of cells undergoing apoptosis in response to AZD8055 treatment was quantified by fluorescenceactivated cell sorter (FACS) flow cytometry using a fluorescein isothiocyanate (FITC)-annexin V Apoptosis Detection Kit (BD, San Jose, CA, USA). All procedures were conducted according to the manufacturer's instructions. Briefly, the cells were treated with AZD8055 or DMSO for $48 \mathrm{~h}$, were washed twice with cold phosphate-buffered saline (PBS), and then resuspended in Binding Buffer at a density of $1 \times 10^{6}$ cells $/ \mathrm{ml}$. FITC-annexin $\mathrm{V}$ and propidium iodide $(\mathrm{PI})$ were added to the cell suspension, and the mixture was incubated for $15 \mathrm{~min}$ at room temperature in the dark. Cell staining was analyzed using a FACScan flow cytometer (FACSCalibur; Becton Dickinson Immunocytometry System, San Jose, CA, USA).

Cell-cycle analysis. The cell-cycle stage of cells treated with AZD8055 was determined using a NucleoCounter ${ }^{\circledR}$ NC-3000 ${ }^{\mathrm{TM}}$ Imaging Cytometer system and a 2-step cell cycle assay kit (ChemoMetec A/S, Allerod, Denmark). All procedures were conducted according to the manufacturer's instructions. Briefly, the cells treated with AZD8055 or DMSO for $48 \mathrm{~h}$ were harvested and washed once with cold PBS, and then suspended in 4',6-diamidino2-phenylindole (DAPI)-containing Lysis Buffer at a concentration of $2 \times 10^{6}$ cells $/ \mathrm{ml}$. After incubation at $37^{\circ} \mathrm{C}$ for $5 \mathrm{~min}$, the cell suspension was mixed with Stabilizing Buffer. The mixture was then imaged and analyzed using NucleoView ${ }^{\circledR}$ NC-3000 software.

Western blot analysis. Total cell lysates were prepared with RIPA buffer (Sigma-Aldrich Chemical Co., St. Louis, MO, USA) containing $1 \times$ protease inhibitor cocktail (Calbiochem, Darmstadt, Germany) and cleared by centrifugation at $20,000 \times g$ for $15 \mathrm{~min}$ at $4^{\circ} \mathrm{C}$. The lysate was mixed with sodium dodecyl sulfate (SDS) sample buffer (250 mM Tris- $\mathrm{HCl}(\mathrm{pH} 6.8), 8 \%$ (w/v) SDS, $20 \%$ (v/v) 2-mercaptoethanol, 40\% (v/v) glycerol, $0.04 \% \quad(\mathrm{w} / \mathrm{v})$ bromophenol blue) and boiled for $5 \mathrm{~min}$. After $3 \mathrm{~min}$ incubation on ice, followed by centrifugation, proteins in the supernatant were separated by SDS polyacrylamide gel (SDS-PAGE). The separated proteins were then transferred to a Hypond ${ }^{\mathrm{TM}}-\mathrm{P}$ hydrophobic polyvinylidene difluoride membrane (GE Healthcare, NJ, USA) in transfer buffer (25 mM Tris base, $192 \mathrm{mM}$ glycine, and $20 \%$ methanol) at $100 \mathrm{~V}$ for $100 \mathrm{~min}$. Following this, the membrane was soaked in HyBlock Blocking Buffer (Goal Bio, Tao Yuan, Taiwan) with gentle shaking for $5 \mathrm{~min}$. The membrane was then incubated with the appropriate primary antibody in blocking buffer at $4^{\circ} \mathrm{C}$ overnight. The following day, the membrane was washed five times (5 min each time) with Tris-buffered saline with Tween-20 [20 mM Tris (pH 7.6), $0.15 \mathrm{M} \mathrm{NaCl}$, and $0.1 \% \mathrm{w} / \mathrm{v}$ Tween-20] on an orbital shaker, followed by incubation with the appropriate horseradish peroxidase-conjugated secondary antibody for $1 \mathrm{~h}$ at room temperature. After the membrane was washed, the horseradish peroxidase conjugated secondary antibodies were detected using an Immobilon Western Chemiluminescent HRP Substrate (Merck Millipore, Billerica, MA, USA). The antibodies used in this study were as follows: rabbit anti-AKT (Abcam, Cambridge, UK), rabbit 
anti-phospho-AKT (anti-p-AKT, Cell Signaling Technology, Danvers, MA, USA), rabbit anti-mTOR (Cell Signaling Technology), rabbit anti-p-mTOR (Cell Signaling Technology), rabbit anti-S6K1 (Santa Cruz Biotechnology, Dallas, TX, USA), rabbit anti-p-S6K1 (Cell Signaling Technology), rabbit antiretinoblastoma $(\mathrm{Rb})$ (Santa Cruz Biotechnology), rabbit anti-p-Rb (Cell Signaling Technology), rabbit anti-cyclin D1 (Abcam), rabbit anti-E2F transcription factor 1 (E2F1) (Abcam), rabbit anti- cyclindependent kinase 2 (CDK2) (Abcam), rabbit-anti-p-CDK2 (Abcam), rabbit anti-p21 (Abcam), rabbit anti-p27 (Abcam), and mouse anti$\beta$-actin (Millipore, Billerica, MA, USA).

Animal studies. The animal experiments in this study were approved by the Committee on Laboratory Animal Research of the Far Eastern Memorial Hospital, Taiwan (103-02-20-A), and conducted according to the guidelines of the Laboratory Animal Center of the Far Eastern Memorial Hospital and adhered to the Guiding Principles in the Care and Use of Animals approved by the Council of the American Physiological Society. The use of animals in this research was under the careful supervision of a person adequately trained in this field and the animals were treated humanely at all times. Male Balb/C mice (4 to 5 weeks old, 20-35 g) were purchased from the National Laboratory Animal Center, Taiwan. The mice were housed in a sterile environment and kept on a $12 \mathrm{~h}$ light/dark cycle (lights on from $6 \mathrm{AM}$ to $6 \mathrm{PM}$ ) at $20^{\circ} \mathrm{C}$. Food and water were provided ad libitum.

To study the antitumor effects of AZD8055 on CT-26 colon cancer in mice, subcutaneous tumors were induced by injecting $2 \times 10^{5}$ CT- 26 cells (in $10 \mu 1$ of PBS) into the right flank of each mouse. The experiment consisted of three groups with seven mice in each group. The day of tumor cell inoculation was designated as Day 0 . The control group received oral gavage of vehicle from day 1 to day 28 . The early treatment group received oral gavage of AZD8055 treatment $(20 \mathrm{mg} / \mathrm{kg}$ per day) $(9,25)$ from day 1 to day 28 . The delayed treatment group received oral gavage of AZD8055 treatment $(20 \mathrm{mg} / \mathrm{kg}$ per day $)$ from day 11 to day 28 . The general appearance and activity of the mice were observed during the treatment period. Tumor size was measured twice a week. Tumor volume was calculated from the formula $\mathrm{V}=1 / 2(\mathrm{~d} 1 \times \mathrm{d} 2 \times \mathrm{d} 3)$, where $\mathrm{d} 1, \mathrm{~d} 2$, and $\mathrm{d} 3$ were tumor diameters as measured with calipers in mutually perpendicular directions. Average daily tumor volumes from each group were compared. All animals were sacrificed after completion of the experiment, and the tumors were harvested.

Statistical analysis. A one-way ANOVA was used for statistical analyses of the extent of cell viability, apoptosis, cell cycle, and the difference in tumor sizes among various groups. Statistical significance was accepted only when $p<0.05$.

\section{Results}

AZD8055 induces cytotoxicity and apoptosis in colon cancer cells. In this study, the antitumor effect of AZD8055 on colon cancer cells was studied. The human HT-15 and HCT116 colon cancer cell lines, and the mouse CT-26 colon cancer cell line, were treated with different concentrations of AZD8055 for $24 \mathrm{~h}$ or $48 \mathrm{~h}$. Following this, cell viability was measured using an MTT assay (Figure 1a). AZD8055 was found to inhibit the proliferation of these three colon cancer cell lines in a time- and concentration-dependent manner $(p<0.05)$. The $\mathrm{LC}_{50} \mathrm{~s}$ for AZD8055 at $24 \mathrm{~h}$ and $48 \mathrm{~h}$ of treatment were $107.8 \mu \mathrm{M}$ and $9.8 \mu \mathrm{M}$ for HCT-15 cells, $124.6 \mu \mathrm{M}$ and $21.5 \mu \mathrm{M}$ for HCT-116 cells, and $3.0 \mu \mathrm{M}$ and $0.43 \mu \mathrm{M}$ for CT-26 cells, respectively. The $\mathrm{LC}_{50} \mathrm{~s}$ for AZD8055 against the human HCT-15 and HCT-116 cells were significantly higher than for the mouse CT-26 cells. In addition, the $48 \mathrm{~h} \mathrm{LC}_{50} \mathrm{~s}$ were $9.1 \%$ to $17.3 \%$ of the $24 \mathrm{~h}$ $\mathrm{LC}_{50} \mathrm{~S}$ in all three of these cell lines. To further investigate the effect on cell viability, apoptosis induction was examined in these colon cancer cells treated with different concentrations of AZD8055 for $48 \mathrm{~h}$. As shown in Figure 1b, AZD8055 treatment caused a significant, concentrationdependent increase in apoptosis of these colon cancer cells $(p<0.05)$. Taken together, these data indicate that AZD8055 induces both cytotoxicity in and apoptosis of these three colon cancer cell lines, and that these cells exhibit different sensitivities to AZD8055.

AZD8055 regulates the AKT/mTOR signaling pathway in colon cancer cells. To explore the mechanism by which AZD8055 inhibits the growth of colon cancer cells, a western blot analysis was used to assess the expression of different proteins in the AKT/mTOR pathway following treatment of colon cancer cells with different concentrations of AZD8055 for $48 \mathrm{~h}$ (Figure 2). While the expression of AKT was not affected by AZD8055, the level of p-AKT was significantly suppressed in a concentration-dependent manner in all three cell lines. In addition, AZD8055 suppressed the expression of mTOR and the levels of pmTOR in HCH-15 and HCT-116 cells, whereas there was no effect on mTOR and p-mTOR in CT-26 cells. AZD8055 also suppressed the expression of S6K1, and the level of p-S6K1, in a concentration-dependent manner in HCT-116 and CT-26 cells. In HCT-15 cells, AZD8055 did not affect S6K1 expression, but it did inhibit the production of p-S6K1. All these data suggest that the AKT-mTOR pathway was inhibited by AZD8055 in these three colon cancer cell lines.

AZD8055 induces cell-cycle arrest in the $G_{0} / G_{1}$ phase in colon cancer cells. Since AZD8055 can down-regulate the activity of S6K1, which is an effector for the mTORdependent control of cell growth and cell-cycle progression $(29,30)$, we next investigated the effects of AZD8055 on cell-cycle progression in these colon cancer cells (Figure 3). After treatment with different concentrations of AZD8055 for $48 \mathrm{~h}$, all three colon cancer cell lines showed accumulation of cells in the $\mathrm{G}_{0} / \mathrm{G}_{1}$ phase, and a decreased level of cells in the $S$ and $\mathrm{G}_{2} / \mathrm{M}$ phases $(p<0.05)$. After treatment with $10 \mu \mathrm{M}$ AZD8055 for $48 \mathrm{~h}$, the mean $\mathrm{G}_{0} / \mathrm{G}_{1}$ fraction was increased from $59.2 \%$ (control) to $90.6 \%$ for HCT-15 cells; from $56.4 \%$ (control) to $80.4 \%$ for HCT-116 cells; and from $54.6 \%$ (control) to $86.6 \%$ for CT-26 cells. 

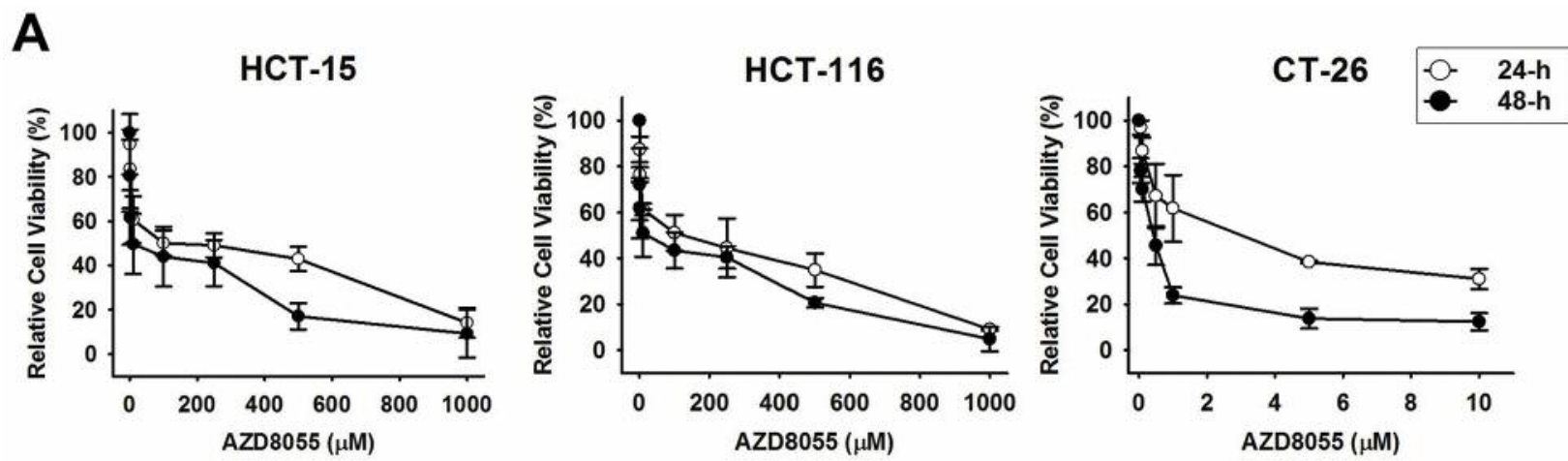

B
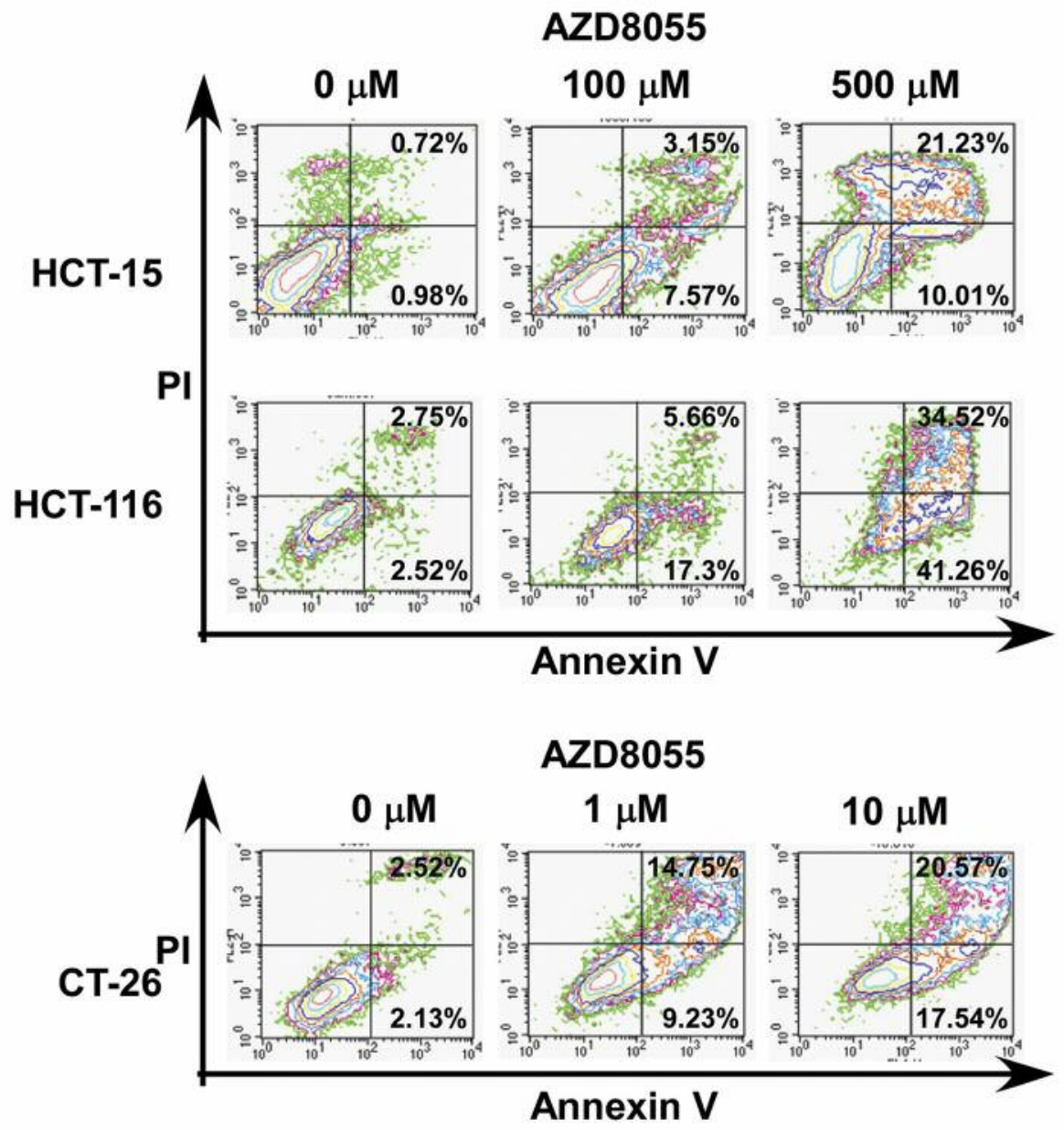

Figure 1. Effects of AZD8055 on the proliferation and apoptosis of colon cancer cells. A: HCT-15, HCT-116, and CT-26 cells were treated with different concentrations of AZD8055 for 24 or $48 \mathrm{~h}$. Cell viability was quantified by the MTT assay, and the relative viability was calculated. B: HCT-15, HCT116, and CT-26 cells were treated with different concentrations of AZD8055 for $48 \mathrm{~h}$, after which the cells were stained with propidium iodidelannexin $V$, and analyzed by flow cytometry. The percentage of cells in early apoptosis (right lower phase) and late apoptosis (right upper phase) are shown.

AZD8055 affects the expression of cell-cycle regulators in colon cancer cells. We further examined the expression of the regulatory proteins involved in the transition from $G_{0} / G_{1}$ phase to $S$ phase (Figure 4). In these three colon cancer cell lines, AZD8055 did not affect Rb expression, whereas it suppressed the level of $\mathrm{p}-\mathrm{Rb}$ in a concentration-dependent manner. AZD8055 also inhibited the expression of CDK2, and of p-CDK2 in these colon cancer cell lines, with the 


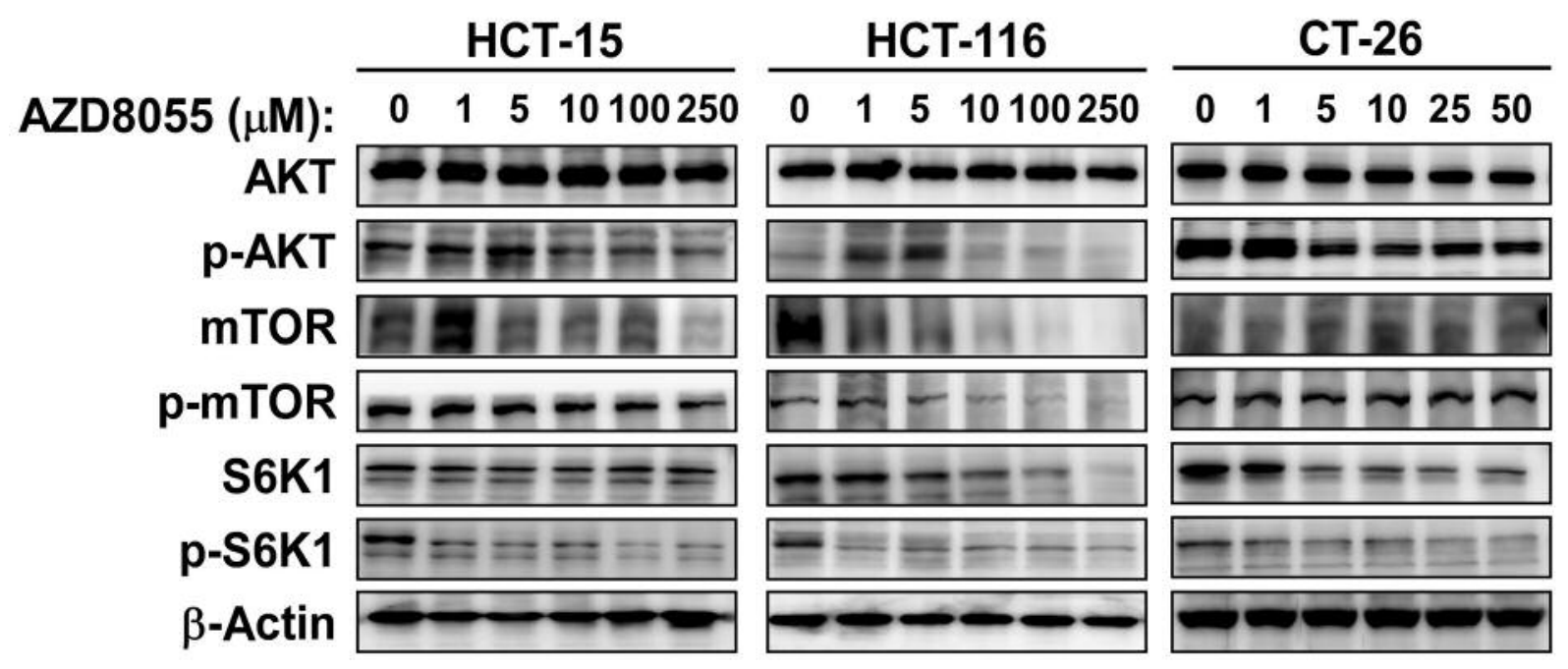

Figure 2. Effect of AZD8055 on the expression of mammalian target of rapamycin (mTOR) signaling proteins in colon cancer cells. HCT-15, HCT116 , and CT-26 colon cancer cells were treated with different concentrations of AZD8055 for $48 \mathrm{~h}$. The levels of protein kinase B (AKT), phosphoAKT (p-AKT), mTOR, p-mTOR, S6 kinase 1 (S6K1), p-S6K1, and $\beta$-actin were analyzed by western blotting.

exception that there was no effect on CDK2 expression in HCT-15 cells. Furthermore, AZD8055 increased the expression of $\mathrm{p} 27$, but did not affect the expression of $\mathrm{p} 21$. In addition, cyclin D1 expression was also suppressed by AZD8055 in these colon cancer cell lines. These data suggest that AZD8055 affects the expression of proteins that regulate the $\mathrm{G}_{0} / \mathrm{G}_{1}-\mathrm{S}$ transition, and thus induce $\mathrm{G}_{0} / \mathrm{G}_{1}$ arrest.

AZD8055 inhibits the tumor growth of subcutaneous CT-26 colon cancer in mice. As the in vitro studies showed that AZD8055 induced significant cytotoxicity, apoptosis, and cellcycle arrest at the $G_{0} / G_{1}$ phase in all three studied colon cancer cells, we further investigated the in vivo effect of AZD8055 on tumor growth in a CT-26 syngeneic tumor model (Figure 5). The AZD8055 treatment was given from day 1 to 28 in the early treatment group, and from day 11 to 28 in the delayed treatment group. The administration of AZD8055 did not induce a significant change in the activity or body weight of mice throughout the treatment course, and all animals survived after completion of the treatment. The early-treatment group showed a significantly slower tumor growth rate than the delayed-treatment group (tumor size on day 28: $198.3 \pm 343.8 \mathrm{~mm}^{3}$ vs. $\left.479.6 \pm 380.9 \mathrm{~mm}^{3} ; p=0.0067\right)$ or the control group (tumor size on Day $28,198.3 \pm 343.8 \mathrm{~mm}^{3}$ vs. $\left.1156.8 \pm 579.1 \mathrm{~mm}^{3} ; p=0.003\right)$. In addition, the tumor growth rate also significantly differed between the delayedtreatment group and the control group was (tumor size on day 28: $479.6 \pm 380.9 \mathrm{~mm}^{3}$ vs. $\left.1156.8 \pm 579.1 \mathrm{~mm}^{3} ; p=0.017\right)$. These data suggest that AZD8055 treatment exerts an antitumor effect on the subcutaneous CT-26 tumor in vivo, and early treatment has a better effect than delayed treatment.

\section{Discussion}

In this study, we found that AZD8055 induced both cytotoxicity and apoptosis in colon cancer cells. The human HT-15 and HCT-116, and mouse CT-26 colon cancer cells were all inhibited by AZD8055 in a concentration- and timedependent manner. The $\mathrm{LC}_{50} \mathrm{~s}$ for AZD8055 at $24 \mathrm{~h}$ of treatment were greater than $100 \mu \mathrm{M}$ for both HCT-15 and HCT-116 cells, and were much higher than the $\mathrm{LC}_{50}$ for CT26 cells. The $\mathrm{LC}_{50}$ s for HCT-15 and HCT-116 cells were similar to those in a previous study, which showed that $10 \mu \mathrm{M}$ AZD8055 treatment for $24 \mathrm{~h}$ only reduced cell viability by $18.5 \%$ in HCT-15 cells and $35.1 \%$ in HCT-116 cells (31). In addition, the $\mathrm{LC}_{50} \mathrm{~s}$ for AZD8055 treatment of the three cell lines studied here were much higher than those reported for most colon cancer cells, which were typically in the range of $30-50 \mathrm{nM}$ at $24 \mathrm{~h}$ of AZD8055 treatment (12). In other cancer types, the $\mathrm{LC}_{50}$ for AZD8055 treatment has been found to be in the nanomolar to low micromolar levels $(13,18,26,27)$. For example, the $\mathrm{LC}_{50}$ for $24 \mathrm{~h}$ AZD8055 treatment in ovarian cancer cells has been reported to be 0.25-2 $\mu \mathrm{M}$ (13). Ten nanomoles of AZD8055 treatment for 24, 48, and $72 \mathrm{~h}$ has also been reported to inhibit both proliferation and glycolysis, and induce apoptosis of cervical cancer HeLa cells (26). These data suggest that there are considerable variations in the sensitivity to AZD8055 in different cancer cell types, such that the $\mathrm{LC}_{50} \mathrm{~s}$ can range widely (over a 1,000-fold) in various cell lines derived from one cancer cell type, such as colon cancer. From this viewpoint, it may therefore be important to differentiate the cancer cells into AZD8055-sensitive and AZD8055resistant before initiating AZD8055 treatment. However, it also 
HCT-15
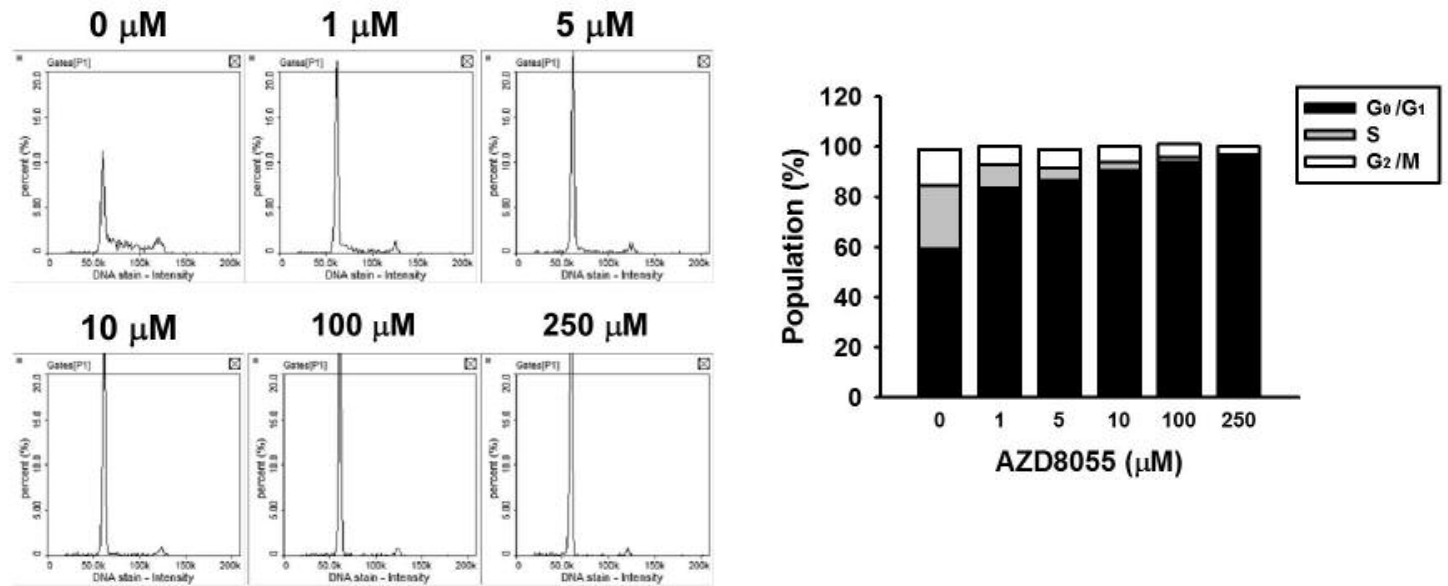

HCT-116
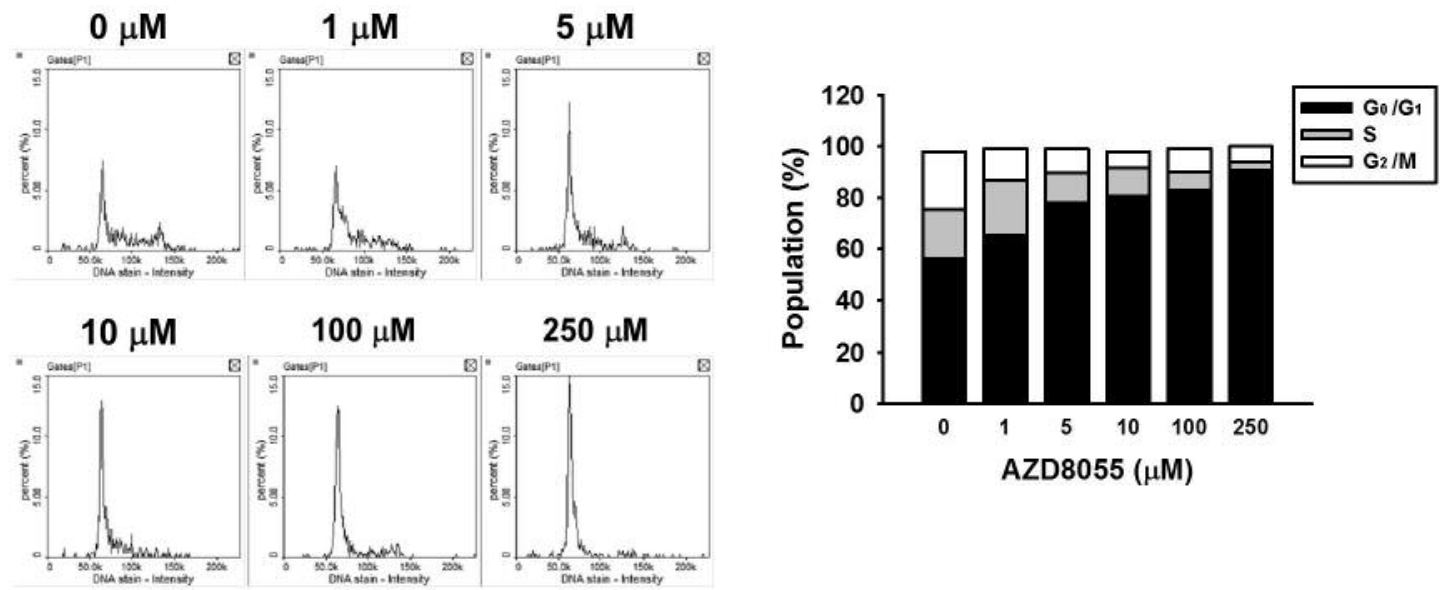

CT-26

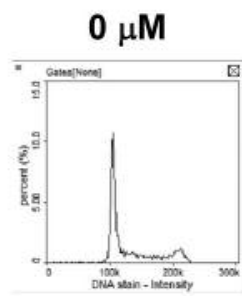

$0.1 \mu \mathrm{M}$
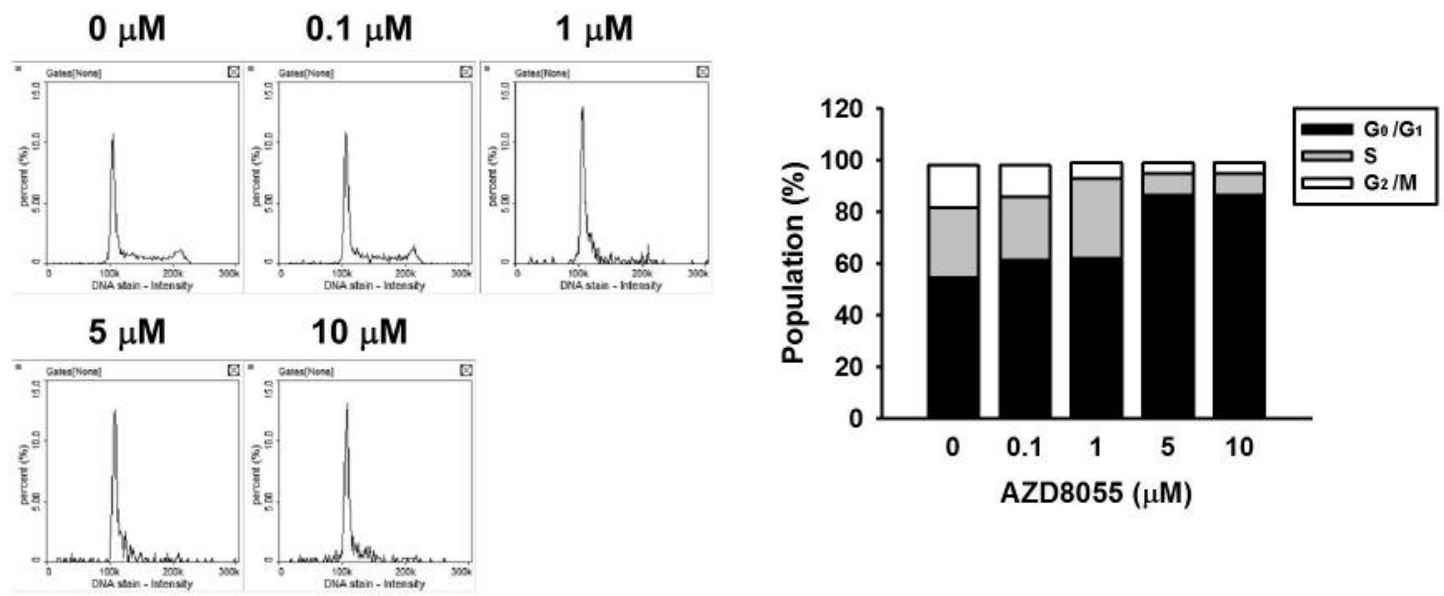

Figure 3. Effect of AZD8055 on cell-cycle distribution in colon cancer cells. HCT-15, HCT-116, and CT-26 cells were treated with different concentrations of AZD8055 for $48 \mathrm{~h}$. The cells were then fixed and the DNA was stained with 4',6-diamidino-2-phenylindole (DAPI). The intensity of DAPI fluorescein was analyzed using an NC-3000 cytometer and the histograms show the percentage of cells in the different phases of the cell cycle. The stacked bar plot represents the collective data from the histograms. 


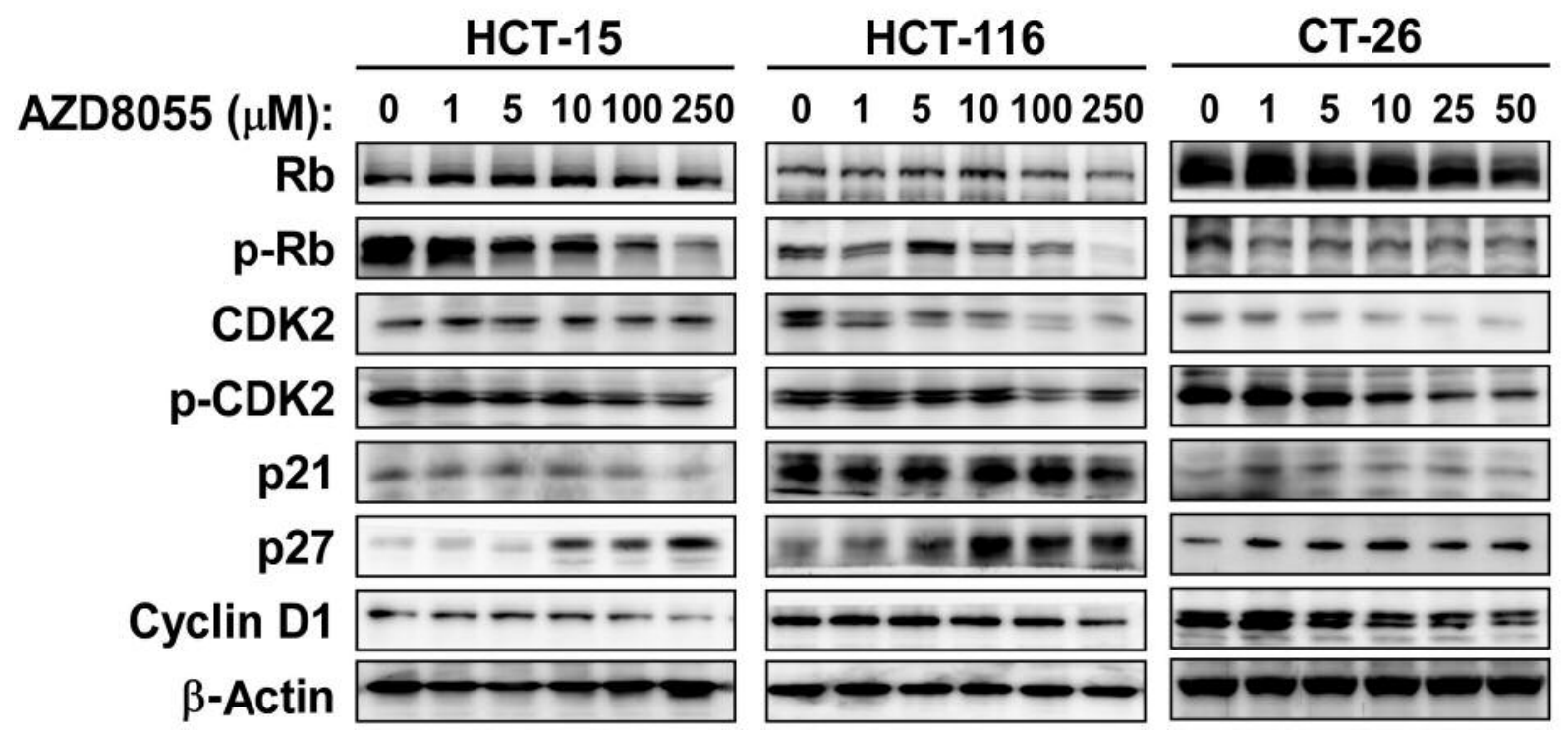

Figure 4. Effect of AZD8055 on the expression of cell-cycle regulators in colon cancer cells. HCT-15, HCT-116, and CT-26 cells were treated with different concentrations of AZD8055 for $48 \mathrm{~h}$. The levels of retinoblastoma (Rb), phospho-Rb (p-Rb), cyclin-dependent kinase 2 (CDK2), $p$-CDK2, p21, p27, cyclin D1, and $\beta$-actin were analyzed by western blotting.
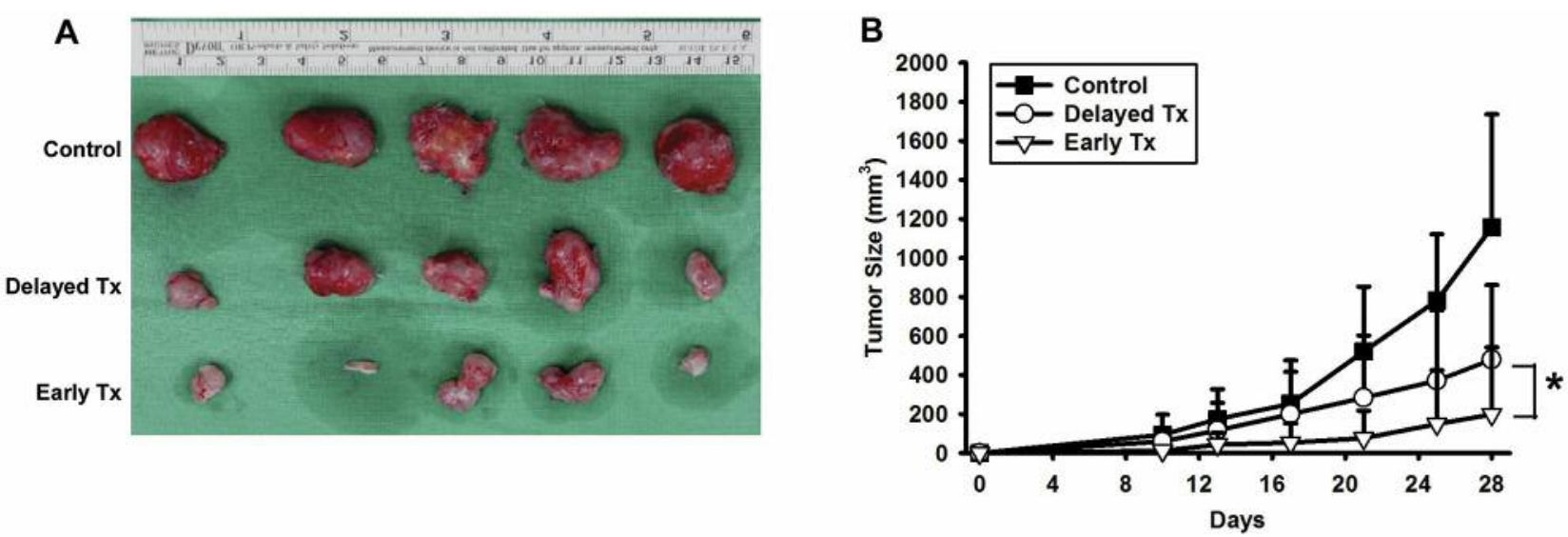

Figure 5. Effect of AZD8055 on the growth of subcutaneous CT-26 tumors in mice. Mice bearing subcutaneous CT-26 tumors were treated with AZD8055. The control group was treated with vehicle from day 1 to day 28 after tumor cell inoculation. The early-treatment group (Early Tx) received AZD8055 treatment from day 1 to day 28 after tumor cell inoculation, and the delayed-treatment group (Delayed Tx) received AZD8055 treatment from day 11 to day 28 after tumor cell inoculation. A: Representative tumor specimens were harvested on day 29 after tumor cell inoculation. B: Tumor growth curves. Data are shown as mean \pm standard deviation. Each point represents the mean volume of tumors for each group. *Significantly different at $p<0.05$.

appears that prolonged AZD8055 treatment may enhance the anticancer effect to a certain extent, since the $\mathrm{LC}_{50} \mathrm{~s}$ with $48 \mathrm{~h}$ of AZD8055 treatment were markedly reduced to $9.1 \%$ to $17.3 \%$ of the $\mathrm{LC}_{50} \mathrm{~s}$ at $24 \mathrm{~h}$ treatment in all three of the cell lines studied here. With respect to apoptosis, the fraction of AZD8055-treated colon cancer cells undergoing apoptosis was lower than the percentage of cell death induced by the same concentration of AZD8055. These data indicate that AZD8055 may cause cell death through induction of apoptosis, as well as through other mechanisms.

The high $\mathrm{LC}_{50} \mathrm{~s}$ for AZD8055 observed for the HCT-15 and HCT-116 cells indicate that they were relatively 
AZD8055-resistant. There is a study showing that the coexistence of mutations in Kirsten rat sarcoma viral oncogene homolog (KRAS) and phosphatidylinositol 4,5bisphosphate 3-kinase catalytic subunit $\alpha$ isoform (PIK3CA) can attenuate the sensitivity to PI3K/mTOR inhibition in colorectal cancer cell lines (2). Because both HCT-15 and HCT-116 cells have PIK3CA and KRAS mutations (2), the drug resistance to AZD8055 seen in these two cell lines may be related to these mutations. CT-26 cells have only the KRAS mutation (2), which may partly explain why these cells were more sensitive to AZD8055 and had a lower $\mathrm{LC}_{50}$ than HCT-15 and HCT-116 cells. AZD8055 is a dual mTOR inhibitor, which can inhibit both mTORC1 and mTORC2 (12). The suppression of mTORC1 and mTORC2 by AZD8055 has been found to occur within $1 \mathrm{~h}$, and such suppression can last for at least $48 \mathrm{~h}$ in colorectal cancer cells (12). In addition, the median relative $\mathrm{IC}_{50}$ for AZD8055 (i.e. the AZD8055 concentration that reduces cell survival by $50 \%$ of the maximum AZD8055 effect) against various Pediatric Preclinical Testing Program cell lines is $24.7 \mathrm{nM}$, and AZD8055 at levels around this concentration significantly suppressed the levels of both p-AKT and p-S6 from 1 to $24 \mathrm{~h}$ after treatment (11). These data indicate that AZD8055 can indeed suppress the mTOR pathway at a low concentration and in a short time. However, the $\mathrm{LC}_{50} \mathrm{~s}$ for the colon cancer cells in this study were relatively high; therefore, we further investigated the effects of AZD8055 on the mTOR pathway. We found the levels of p-AKT, p-mTOR, and p-S6K1 were suppressed by AZD8055 in a concentration-dependent manner, indicating that both the mTORC1 and mTORC2 pathways were inhibited. The concentrations needed to suppress the levels of these phosphoproteins were in the range of 1-10 $\mu \mathrm{M}$, which are higher than those in a previous study (11).

mTOR has been noted to regulate cell-cycle progression, whereas S6K1 is known to be an effector for mTORdependent cell-cycle progression $(29,30,32)$. AZD8055 can also suppress the level of p-S6K1; therefore, it may affect cell-cycle progression. We found that AZD8055 treatment induced a concentration-dependent accumulation of colon cancer cells in the $G_{0} / G_{1}$ phase. These results were consistent with previous studies, which showed that AZD8055 causes $\mathrm{G}_{0} / \mathrm{G}_{1}$ arrest in both $\mathrm{SW} 620$ colorectal cancer cells and ovarian cancer cells $(12,13)$. However, the cell lines described in the previous studies are more sensitive to AZD8055 than HCT-15 and HCT-116 cells, with $24 \mathrm{~h}$ $\mathrm{LC}_{50} \mathrm{~s}$ for AZD8055 treatment in the nanomolar to low micromolar range. For example, treatment of SW620 cells with $1 \mu \mathrm{M}$ AZD8055 for $24 \mathrm{~h}$ has been reported to induce a loss of cyclin D1 and cause $\mathrm{G}_{1}$ cell-cycle arrest $(12,13)$. In contrast, in AZD8055-resistant SW620 cells, induced by repeated AZD8055 challenge, treatment with $2 \mu \mathrm{M}$ AZD8055 for $24 \mathrm{~h}$ showed only a mild decrease in the expression of cyclin D1, which was different from that of the parental SW620 cells (12). These data suggest AZD8055 might not necessarily be able to affect cell-cycle progression in AZD8055-resistant cells. However, our study showed that AZD8055 induced significant $\mathrm{G}_{0} / \mathrm{G}_{1}$ arrest, in a concentration-dependent manner, in these drug-resistant colon cancer cells.

Progression through the cell cycle is regulated by CDKs, whose activity is inhibited by CDK inhibitors $(33,34)$. Cyclin D binds to CDK4/6 to form the cyclin D-CDK4/6 complex, which in turn phosphorylates $\mathrm{Rb}$ and allows it to dissociate from the $\mathrm{E} 2 \mathrm{~F} / \mathrm{Rb}$ complex, thus, activating $\mathrm{E} 2 \mathrm{~F}(33,34)$. Activation of $\mathrm{E} 2 \mathrm{~F}$ results in an increase in the transcription of various genes such as cyclin E. Cyclin E then binds to CDK2, forming the cyclin E-CDK2 complex, which pushes the cell from the $G_{1}$ to the $S$ phase $(33,34)$. CDK inhibitors, such as p21 and p27, may halt the cell cycle in the $G_{1}$ phase, by binding to and inactivating cyclin-CDK complexes (33, 34). PI3K/AKT/mTOR/S6K1 signaling mediates $\mathrm{G}_{1}$ progression and cyclin expression, increases the translation of positive cell-cycle regulators, such as cyclin D1, and reduces the expression of p27 $(33,35)$. Therefore, mTOR inhibitors can inhibit the $\mathrm{G}_{1}-\mathrm{S}$ transition. The mTOR inhibitor rapamycin has been found to inhibit the $G_{1}-S$ progression and the expression of cyclin D1, CDK4, and Rb phosphorylation in prostate cancer cells (32-34). In addition, AZD8055 can increase $\mathrm{Rb}$ expression and the levels of $\mathrm{pRb}$ in breast cancer cells (36). To confirm the inhibition of cell cycle progression by AZD8055 in colon cancer cells, we further investigated the effect of AZD8055 on the expression of regulatory proteins involved in the phase transition between the $\mathrm{G}_{1}$ and $\mathrm{S}$ phases in AZD8055-resistant HCT-15 and HCT-116 cells, and CT-26 cells. In these three cell lines, the levels of $\mathrm{p}-\mathrm{Rb}$ and p-CDK2 decreased, and the expression of p27 increased, although the expression of p21 was not significantly changed. These data suggest that AZD8055 can modulate the activity of mTOR-dependent cell cycle regulators and cause $\mathrm{G}_{1}$ arrest in colon cancer cells, even in AZD8055-resistant cells.

As the in vitro studies showed that AZD8055 induced significant cytotoxicity and apoptosis in colon cancer cells, we further investigated the in vivo antitumor effects of AZD8055 in a CT-26 syngeneic mouse model. We found that both early and delayed AZD8055 treatments exerted antitumor effects on the subcutaneous CT-26 tumors, with early treatment having a stronger antitumor effect than delayed treatment. Previously, AZD8055 had been shown to exert a tumor reducing effect in a cis-Apc/Smad4 mouse model of locally invasive intestinal adenocarcinoma (9). In this mouse tumor model, the intestinal adenomas begin to progress into invasive adenocarcinomas when the mice are around 12 weeks of age, and $55 \%$ of the tumors show an invasive pattern when the mice were 20 weeks of age (37). In the previous study, the $c i s-A p c / S m a d 4$ mice were treated 
with AZD8055 from 12 to 20 weeks of age (9). Because the AZD8055 treatment was started in the beginning of tumor progression (9), such treatment is more likely an early or prophylactic treatment. In addition, this intestinal adenomastumor model is relatively heterogeneous (37). The mice had increased polyp sizes and numbers in both the small and large intestines; some mice developed carcinomas in the duodenal papilla of Vater, and more than half had epidermoid cysts of the skin (37). Therefore, this animal model is significantly different from the colon cancer model. Another xenograft model used LoVo or SW620 colon cancer cells to induce subcutaneous tumors, and $10 \mathrm{mg} / \mathrm{kg}$ AZD8055 was shown to inhibit about $70 \%$ of tumor growth in these LoVo and SW620 colon cancer cell xenografts $(8,25)$. However, these two cell lines are AZD8055-sensitive, with $\mathrm{LC}_{50} \mathrm{~s}$ at the nanomolar level. AZD8055 thus has a significant antitumor effect on the xenografts derived from these two cell lines (12). The $\mathrm{LC}_{50}$ after $24 \mathrm{~h}$ AZD8055 treatment of CT-26 cells was $3 \mu \mathrm{M}$, being about 100 fold-higher than the $\mathrm{LC}_{50} \mathrm{~s}$ of $\mathrm{LoVo}$ and SW620 cells. Therefore, the CT-26 tumor model differs significantly from both the cis-Apc/Smad4 mouse model of locally invasive intestinal adenocarcinoma and the LoVo and SW620 colon cancer cell xenograft models. The data from the CT-26 tumor model more likely represent colon cancer with moderate resistance to AZD8055.

From the above data, we found that AZD8055 can suppress the mTOR pathway and modulate mTOR-dependent cell-cycle regulators to induce cytotoxicity, apoptosis, and $G_{0} / G_{1}$ cell cycle arrest in colon cancer cells, even in the AZD8055resistant HCT-15 and HCT-116 cells. In addition, an in vivo study showed that AZD8055 exerted an antitumor effect on the CT-26 subcutaneous tumors in mice. The $\mathrm{LC}_{50}$ for AZD8055 in the HCT-15 and HCT-116 cells was greater than $100 \mu \mathrm{M}$, which indicates that single drug treatment using AZD8055 might not be effective to treat these drug-resistant colon cancers. In addition, the dose of AZD8055 is limited by the side-effects of elevated serum transaminase levels noted in the clinical trial for the treatment of advanced solid tumors and lymphoma (15). Therefore, modification of the dosing schedule, or combination treatment with a lower dose of AZD8055 and other anticancer drugs may be necessary to mitigate the adverse effects and enhance the therapeutic efficacy (18). Treatment of Apc/Smad4 mice with AZD8055 has been found to increase epidermal growth factor receptor (EGFR) and mitogen-activated protein kinase kinase (MEK)/extracellular signal-regulated kinase (ERK) signaling in tumor epithelial and stromal cells (9). Further, a combination of MEK $1 / 2$ inhibitors or checkpoint kinase 1 (CHK1) inhibitors with mTOR inhibitors can have a synergistic effect on cancers $(12,38)$. Therefore, co-administration of AZD8055 and an EGFR inhibitor or MEK inhibitor may induce synergistic antitumor effects on colon cancer (9). Further studies will be required to clarify these issues.

\section{Conflicts of Interest}

The Authors do not have any conflicts of interest to declare in regard to this study.

\section{Acknowledgements}

This work was supported by the Far Eastern Memorial Hospital, Taiwan, R.O.C. [grant numbers FEMH-2015- 039 and FEMH-2017C-041].

\section{References}

1 Siegel R, Naishadham D and Jemal A: Cancer statistics, 2012. CA Cancer J Clin 62: 10-29, 2012.

2 Wang XW and Zhang YJ: Targeting mTOR network in colorectal cancer therapy. World J Gastroenterol 20: 4178-4188, 2014.

3 He K, Zheng X, Li M, Zhang L and Yu J: mTOR inhibitors induce apoptosis in colon cancer cells via CHOP-dependent DR5 induction on 4E-BP1 dephosphorylation. Oncogene 35: 148-157, 2016.

4 Vogelstein B, Papadopoulos N, Velculescu VE, Zhou S, Diaz LA Jr. and Kinzler KW: Cancer genome landscapes. Science 339: 1546-1558, 2013.

5 Francipane MG and Lagasse E: mTOR pathway in colorectal cancer: an update. Oncotarget 5: 49-66, 2014.

6 Gulhati P, Cai Q, Li J, Liu J, Rychahou PG, Qiu S, Lee EY, Silva SR, Bowen KA, Gao T and Evers BM: Targeted inhibition of mammalian target of rapamycin signaling inhibits tumorigenesis of colorectal cancer. Clin Cancer Res 15: 7207-7216, 2009.

7 Wen M, Li B, Cao X, Weng C, Wu Y, Fang X, Zhang X and Liu G: Clinical significance of aberrant mammalian target of rapamycin expression in stage IIIB colon cancer. Oncol Lett 8 : 1080-1086, 2014.

8 Chresta CM, Davies BR, Hickson I, Harding T, Cosulich S, Critchlow SE, Vincent JP, Ellston R, Jones D, Sini P, James D, Howard Z, Dudley P, Hughes G, Smith L, Maguire S, Hummersone M, Malagu K, Menear K, Jenkins R, Jacobsen M, Smith GC, Guichard S and Pass M: AZD8055 is a potent, selective, and orally bioavailable ATP-competitive mammalian target of rapamycin kinase inhibitor with in vitro and in vivo antitumor activity. Cancer Res 70: 288-298, 2010.

9 Fujishita T, Kojima Y, Kajino-Sakamoto R, Taketo MM and Aoki M: Tumor microenvironment confers mTOR inhibitor resistance in invasive intestinal adenocarcinoma. Oncogene 36 : 6480-6489, 2017.

10 Meric-Bernstam F and Gonzalez-Angulo AM: Targeting the mTOR signaling network for cancer therapy. J Clin Oncol 27: 2278-2287, 2009.

11 Houghton PJ, Gorlick R, Kolb EA, Lock R, Carol H, Morton CL, Keir ST, Reynolds CP, Kang MH, Phelps D, Maris JM, Billups $C$ and Smith MA: Initial testing (stage 1) of the mTOR kinase inhibitor AZD8055 by the pediatric preclinical testing program. Pediatr Blood Cancer 58: 191-199, 2012.

12 Cope CL, Gilley R, Balmanno K, Sale MJ, Howarth KD, Hampson M, Smith PD, Guichard SM and Cook SJ: Adaptation to mTOR kinase inhibitors by amplification of eIF4E to maintain cap-dependent translation. J Cell Sci 127: 788-800, 2014. 
13 Pétigny-Lechartier C, Duboc C, Jebahi A, Louis MH, Abeilard E, Denoyelle C, Gauduchon P, Poulain L and Villedieu M: The mTORC1/2 inhibitor AZD8055 strengthens the efficiency of the MEK inhibitor trametinib to reduce the MCL-1/[BIM and PUMA] ratio and to sensitize ovarian carcinoma cells to ABT737. Mol Cancer Ther 16: 102-115, 2017.

14 Asahina H, Nokihara H, Yamamoto N, Yamada Y, Tamura Y, Honda K, Seki Y, Tanabe Y, Shimada H, Shi X and Tamura T: Safety and tolerability of AZD8055 in Japanese patients with advanced solid tumors; a dose-finding phase I study. Invest New Drugs 31: 677-684, 2013.

15 Naing A, Aghajanian C, Raymond E, Olmos D, Schwartz G, Oelmann E, Grinsted L, Burke W, Taylor R, Kaye S, Kurzrock $\mathrm{R}$ and Banerji U: Safety, tolerability, pharmacokinetics and pharmacodynamics of AZD8055 in advanced solid tumours and lymphoma. Br J Cancer 107: 1093-1099, 2012.

16 Johnsen JI, Segerström L, Orrego A, Elfman L, Henriksson M, Kågedal B, Eksborg S, Sveinbjörnsson B and Kogner P: Inhibitors of mammalian target of rapamycin down-regulate MYCN protein expression and inhibit neuroblastoma growth in vitro and in vivo. Oncogene 27: 2910-2922, 2008.

17 Shaw RJ and Cantley LC: Ras, PI(3)K and mTOR signalling controls tumour cell growth. Nature 441: 424-430, 2006.

18 Chen Y, Tsai YH, Tseng BJ, Pan HY and Tseng SH: Suppression of miR-19b enhanced the cytotoxic effects of mTOR inhibitors in human neuroblastoma cells. J Pediatr Surg 51: 1818-1825, 2016.

19 Hu M, Huang H, Zhao R, Li P, Li M, Miao H, Chen N and Chen M: AZD8055 induces cell death associated with autophagy and activation of AMPK in hepatocellular carcinoma. Oncol Rep 31: 649-656, 2014.

20 Luchman HA, Stechishin OD, Nguyen SA, Lun XQ, Cairncross JG and Weiss S: Dual mTORC1/2 blockade inhibits glioblastoma brain tumor initiating cells in vitro and in vivo and synergizes with temozolomide to increase orthotopic xenograft survival. Clin Cancer Res 20: 5756-5767, 2014.

21 Serova M, de Gramont A, Tijeras-Raballand A, Dos Santos C, Riveiro ME, Slimane $K$, Faivre $S$ and Raymond $E$ : Benchmarking effects of mTOR, PI3K, and dual PI3K/mTOR inhibitors in hepatocellular and renal cell carcinoma models developing resistance to sunitinib and sorafenib. Cancer Chemother Pharmacol 71: 1297-1307, 2013.

22 Sini P, James D, Chresta C and Guichard S: Simultaneous inhibition of mTORC1 and mTORC 2 by mTOR kinase inhibitor AZD8055 induces autophagy and cell death in cancer cells. Autophagy 6: 553-554, 2010.

23 Wei F, Liu Y, Guo Y, Xiang A, Wang G, Xue X and Lu Z: miR$99 \mathrm{~b}$-targeted mTOR induction contributes to irradiation resistance in pancreatic cancer. Mol Cancer 12: 81, 2013.

24 Zhao L, Teng B, Wen L, Feng Q, Wang H, Li N, Wang Y and Liang Z: mTOR inhibitor AZD8055 inhibits proliferation and induces apoptosis in laryngeal carcinoma. Int J Clin Exp Med 7: 337-347, 2014.

25 Faber AC, Coffee EM, Costa C, Dastur A, Ebi H, Hata AN, Yeo AT, Edelman EJ, Song Y, Tam AT, Boisvert JL, Milano RJ, Roper J, Kodack DP, Jain RK, Corcoran RB, Rivera MN, Ramaswamy S, Hung KE, Benes CH and Engelman JA: mTOR inhibition specifically sensitizes colorectal cancers with KRAS or BRAF mutations to BCL-2/BCL-XL inhibition by suppressing MCL-1. Cancer Discov 4: 42-52, 2014.
26 Li S, Li Y, Hu R, Li W, Qiu H, Cai H and Wang S: The mTOR inhibitor AZD8055 inhibits proliferation and glycolysis in cervical cancer cells. Oncol Lett 5: 717-721, 2013.

27 Qi L, Toyoda H, Xu DQ, Zhou Y, Sakurai N, Amano K, Kihira $\mathrm{K}$, Hori H, Azuma E and Komada Y: PDK1-mTOR signaling pathway inhibitors reduce cell proliferation in MK2206 resistant neuroblastoma cells. Cancer Cell Int 15: 91, 2015.

28 Corbett TH, Griswold DP Jr., Roberts BJ, Peckham JC and Schabel FM Jr.: Tumor induction relationships in development of transplantable cancers of the colon in mice for chemotherapy assays, with a note on carcinogen structure. Cancer Res 35: 2434-2439, 1975.

29 Fingar DC, Richardson CJ, Tee AR, Cheatham L, Tsou C and Blenis J: mTOR controls cell-cycle progression through its cell growth effectors S6K1 and 4E-BP1/eukaryotic translation initiation factor 4E. Mol Cell Biol 24: 200-216, 2004.

30 Zhou X, Liu W, Hu X, Dorrance A, Garzon R, Houghton PJ and Shen C: Regulation of CHK1 by mTOR contributes to the evasion of DNA damage barrier of cancer cells. Sci Rep 7: 1535, 2017.

31 Risberg K, Redalen KR, Sonstevold L, Bjornetro T, Solvernes J and Ree AH: Pro-survival responses to the dual inhibition of anti-apoptotic BCL-2 family proteins and mTOR-mediated signaling in hypoxic colorectal carcinoma cells. BMC Cancer 16: $531,2016$.

32 Gao N, Zhang Z, Jiang $\mathrm{BH}$ and Shi X: Role of $\mathrm{PI} 3 \mathrm{~K} / \mathrm{AKT} / \mathrm{mTOR}$ signaling in the cell-cycle progression of human prostate cancer. Biochem Biophys Res Commun 310: 1124-1132, 2003.

33 Gao N, Flynn DC, Zhang Z, Zhong XS, Walker V, Liu KJ, Shi $\mathrm{X}$ and Jiang BH: G1 cell cycle progression and the expression of $\mathrm{G} 1$ cyclins are regulated by $\mathrm{PI} 3 \mathrm{~K} / \mathrm{AKT} / \mathrm{mTOR} / \mathrm{p} 70 \mathrm{~S} 6 \mathrm{~K} 1$ signaling in human ovarian cancer cells. Am J Physiol Cell Physiol 287: C281-291, 2004.

34 Zhuang Y and Miskimins WK: Cell cycle arrest in metformintreated breast cancer cells involves activation of AMPK, downregulation of cyclin D1, and requires $\mathrm{p} 27^{\mathrm{Kip} 1}$ or $\mathrm{p} 21^{\mathrm{Cip} 1}$. J Mol Signal 3: 18, 2008.

35 Hong F, Larrea MD, Doughty C, Kwiatkowski DJ, Squillace R and Slingerland JM: mTOR-raptor binds and activates SGK1 to regulate p27 phosphorylation. Mol Cell 30: 701-711, 2008.

36 Sharma S, Yao HP, Zhou YQ, Zhou J, Zhang R and Wang MH: Prevention of BMS-777607-induced polyploidy/senescence by mTOR inhibitor AZD8055 sensitizes breast cancer cells to cytotoxic chemotherapeutics. Mol Oncol 8: 469-482, 2014.

37 Takaku K, Oshima M, Miyoshi H, Matsui M, Seldin MF and Taketo MM: Intestinal tumorigenesis in compound mutant mice of both Dpc4 (Smad4) and Apc genes. Cell 92: 645-656, 1998.

38 Massey AJ, Stephens P, Rawlinson R, McGurk L, Plummer R and Curtin NJ: mTORC1 and DNA-PKCs as novel molecular determinants of sensitivity to CHK1 inhibition. Mol Oncol 10: 101-112, 2016. 